\title{
A Novel Direct Power Control for Open-winding Brushless Doubly-fed Reluctance Generators Fed by Dual Two-level Converters Using a Common DC Bus
}

\author{
Liancheng Zhu ${ }^{1,2}$, Fengge Zhang ${ }^{1}$, \\ Shi Jin ${ }^{1}$, Siyang Yu ${ }^{1}$ \\ 1 School of Electrical Engineering \\ Shenyang University of Technology \\ Shenyang, China \\ 2 School of Electronic and Information \\ Engineering \\ University of Science and Technology \\ Liaoning \\ Anshan, China \\ E-mail: zhuliancheng@163.com
}

\author{
Sul Ademi \\ Institute for Energy and Environment, \\ Department of Electronic and Electrical \\ Engineering \\ University of Strathclyde \\ Glasgow, United Kingdom \\ E-mail: sul.ademiphd@yahoo.com
}

\author{
Wenping Cao \\ School of Engineering and Applied \\ Science \\ Aston University \\ Birmingham, United Kingdom \\ E-mail: w.p.cao@aston.ac.uk
}

\begin{abstract}
A new direct power control (DPC) strategy for openwinding brushless doubly-fed reluctance generators (BDFRGs) with variable speed constant frequency is proposed. The control winding is open-circuited and fed by dual traditional two-level three phase converters using a common DC bus, and the DPC strategy aiming at maximum power point tracking and common mode voltage elimination is designed. Compared to the traditional three-level converter systems, the DC bus voltage, the voltage rating of power devices and capacity of the single two-level converter are all reduced by $50 \%$ while the reliability, redundancy and fault tolerance of the proposed system still greatly improved. Consequently its effectiveness is evaluated by simulation tests on a $42 \mathrm{~kW}$ prototype generator in MATLAB/SIMULINK.
\end{abstract}

Keywords-Brushless doubly-fed reluctance generator (BDFRG); direct power control; variable speed constant frequency; openwinding; common mode voltage (CMV).

\section{INTRODUCTION}

Brushless doubly-fed machines (BDFMs) are the evolution of cascaded induction machine [1], which have been investigated as a probable alternative to the existing solutions in variable speed applications with limited speed ranges during the last decade [1]-[3], [5]-[12], [15], [16]. The main motivation for this increasing interest is due to its advantages of reasonable cost, high reliability of brushless structure and maintenance-free as well as competitive performance [1], [2]. As a member of the slip power recovery family, BDFMs have the high cost benefits of partially-rated inverter being just $25 \%$ of machine rating for a typical speed range of 2:1 in pump drives or wind turbines [2]. Another interesting advantage of the BDFMs is the running

This work was supported by National Natural Science Foundation of China (51537007, 51277124), the Natural Science Foundation of Liaoning Province, China (Grant No. 201602540) and Youth Foundation of University of Science and Technology Liaoning (2012QN29). mode flexibility, it can operate as a doubly-fed machine, induction machine (when inverter failed) or synchronous machine (when either winding supplied by DC-link) [1], [2].

Apart from the above features, the absence of rotor windings makes the brushless doubly-fed reluctance generator (BDFRG) more efficient [2], inherently decoupled control of the active power/torque and reactive power with doubly-fed induction generator (DFIG) [2], [3], easier to model/control compared to the doubly-excited wound rotor induction machine and brushless doubly-fed induction machine [2], [3], and without the cost of fully-rated inverter and demagnetization in permanent magnet synchronous generators [5]. Researches on the control of BDFRG involved of the scalar control (SC) [3], voltage and/or flux (field) oriented control [5], [6], additionally, the disturbance rejection abilities of the BDFRG controller(s) have been further explored in [15], [16], direct torque control (DTC) [7], [8]. Recently, a new strategy termed as "direct power control (DPC)" derived from DTC has been presented [9], but in power control sense, the DPC is virtually "indirect", so called DPC is just considering the formal similarity with DTC. A typical topology of BDFRG consists of two sets of standard, sinusoidally distributed three-phase stator windings of normally different applied pole numbers and frequencies, with a rotor having half of the total stator poles to provide the rotor position dependent magnetic coupling between the windings and torque production as shown in Fig. 1 [2], [3]. The power/primary winding is grid-connected, its pole pairs and frequency is $p_{p}$ and $f_{p}$; the control/secondary winding (with $p_{c}$ and $f_{c}$ ) is fed by a standard back-to-back converter. 
In this paper, considering the rated capacity limits of traditional two-level converter systems [10] and advantages of traditional three-level converters systems [11], a novel DPC strategy applied to open-winding BDFRG is proposed [12]-[14] as shown in Fig. 2, where the control winding is open-circuited and fed by dual traditional two-level converters termed as MSC1, MSC2 (machine side converter, MSC) using a common DC bus (hence a single grid side converter, GSC), meanwhile, an optimized PWM scheme with common mode voltage (CMV) elimination has been implemented. Compared to the traditional three-level converter systems [11], the reliability, redundancy and fault tolerance of the proposed system are greatly improved while the DC-link voltage and the rated capacity of power devices in MSC can be reduced about $50 \%$, but the complexity in main circuit topology is not almost increased.

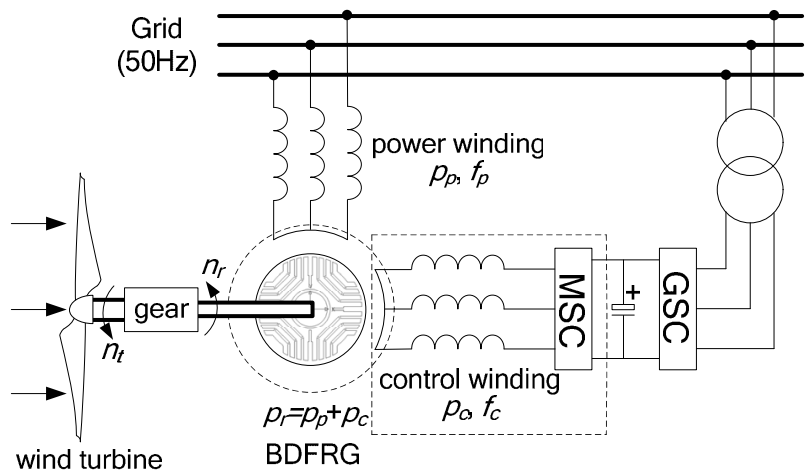

Fig. 1. Schematic diagram of the BDFRG for wind turbine.

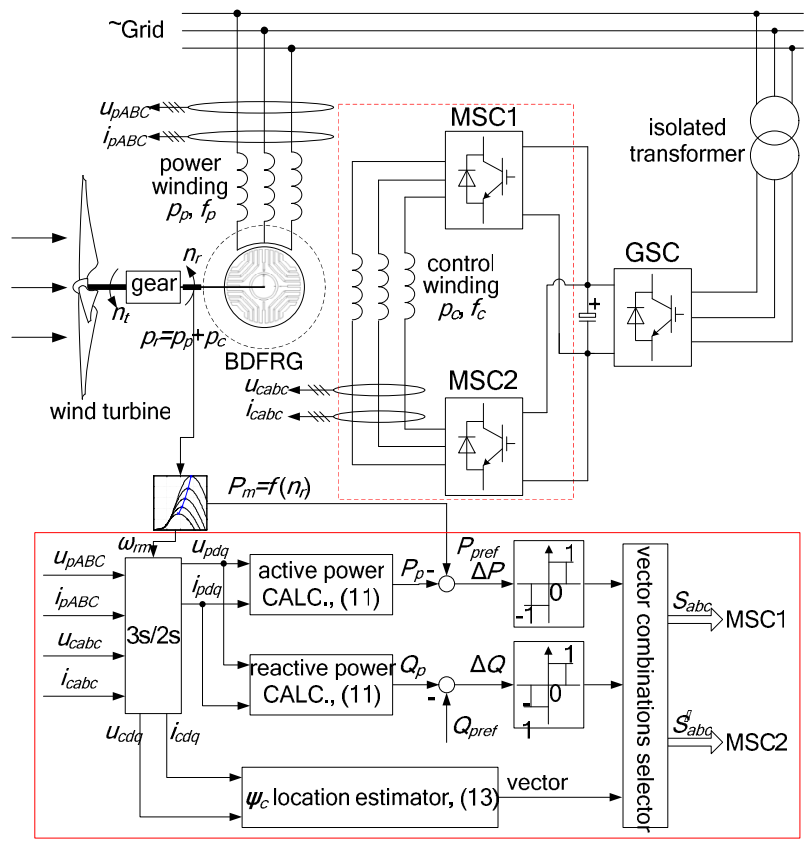

Fig. 2. Principle diagram of the proposed DPC strategy.

\section{BDFRG FUNDMENTALS}

\section{A. BDFRG Model}

To better understand the underlying principle of the BDFRG, in arbitrary rotating $d-q$ reference frames as illustrated in Fig. 3, the dynamic model using standard notation for generating convention can be represented as (1), (2) [2], [3],

$$
\left\{\begin{array}{l}
u_{p q}=-R_{p} i_{p q}-p\left(L_{p}-L_{p c}\right) i_{p q}-p\left[L_{p c}\left(i_{p q}-i_{p q}\right)\right]+\omega \psi_{p d} \\
u_{p d}=-R_{p} i_{p d}-p\left(L_{p}-L_{p c}\right) i_{p d}-p\left[L_{p c}\left(i_{p d}-i_{c d}\right)\right]+\omega \psi_{p q} \\
u_{c q}=R_{c} i_{c q}+p\left(L_{c}-L_{p c}\right) i_{c q}+p\left[L_{p c}\left(i_{c q}-i_{p q}\right)\right]-\left(\omega_{r}-\omega\right) \psi_{c d} \\
u_{c d}=R_{c} i_{c d}+p\left(L_{c}-L_{p c}\right) i_{c d}+p\left[L_{p c}\left(i_{p d}-i_{p d}\right)\right]-\left(\omega_{r}-\omega\right) \psi_{c q}
\end{array}\right.
$$

$$
\left\{\begin{array}{l}
\psi_{p q}=L_{p} i_{p q}-L_{p c} i_{c q} \\
\psi_{p d}=L_{p} i_{p d}+L_{p c} i_{c d} \\
\psi_{c q}=L_{c} i_{c q}-L_{p c} i_{p q} \\
\psi_{c d}=L_{c} i_{c d}+L_{p c} i_{p d}
\end{array}\right.
$$

where the letter " $p$ " denotes the differential operator, the subscripts " $p$ ", " $c$ ", " $r$ ", " $d$ ", " $q$ " denote the power winding, control winding, rotor components and their $d q$ components, respectively; $L_{p}, L_{c}$ and $L_{p c}$ indicate the self-inductance and the mutual inductance between the two stator windings; $\omega, \omega-\omega_{r}$ and $\omega_{r}$ represent the rotation speed of $d_{p}-q_{p}, d_{c}-q_{c}$ frame and the rotor angular speed, where the stator and rotor equations are referred to the same frame. Note that if $\omega=\omega_{p}, \omega_{r}-\omega=\omega_{c}$, i.e., the two stator windings are both in the same static reference frame.

\section{B. Principles of BDFRG with VSCF}

As shown in Fig. 1, 2, the relationship between the frequency (or electrical angular velocity), poles and speed (or angular velocity) of the BDFRG is expressed as (3), (4) [2], [5], [6], where $n_{r}$ $(\mathrm{rpm})$ and $\omega_{r m}=2 \pi n_{r} / 60(\mathrm{rad} / \mathrm{s})$ denote the rotor speed and its angular velocity; $n_{r 0}$ and $\omega_{s y n}$ denote the synchronous speed and its angular velocity, i.e., $f_{c}=0, n_{r 0}=60 f_{p} / p_{r}$, respectively; $s=$ $\omega_{c} / \omega_{p}$ is the generalised slip.

$$
\begin{gathered}
f_{p}=\frac{n_{r}\left(p_{p}+p_{c}\right)}{60} \pm f_{c} \\
\omega_{r m}=\frac{2 \pi n_{r}}{60}=\frac{\omega_{p}+\omega_{c}}{p_{r}}=\frac{\omega_{p}}{p_{r}} \cdot\left(1+\frac{\omega_{c}}{\omega_{p}}\right)=\omega_{s y n} \cdot(1-s)
\end{gathered}
$$

Using (4), the mechanical power equation showing individual contributions of the two stator windings with a rotor can be easily established as (5),

$$
P_{m}=T_{e m} \cdot \omega_{r m}=\underbrace{T_{e m} \cdot \frac{\omega_{p}}{p_{r}}}_{P_{p m} \approx P_{p}}+\underbrace{T_{e m} \cdot \frac{\omega_{c}}{p_{r}}}_{P_{c m} \approx P_{c}}=P_{p m} \cdot(1-s)
$$


obviously, in generating (BDFRG) convention, $P_{m}<0, T_{e m}<0$, $P_{p m}<0$, where only $P_{p m}$ (i.e., $P_{p}$ ) component is concerned by the subsequent DPC strategy in section III. Notice that $P_{c m}<0$ for "super-synchronous" $\left(\omega_{c}>0\right)$ and $P_{c m}>0$ for "subsynchronous" $\left(\omega_{c}<0\right)$ mode. It's unusual electromagnetic torque expression can be found as (6) [2],

$$
T_{e m}=\frac{3 p_{r}}{2 \sigma L_{c}}\left|\boldsymbol{\psi}_{p c} \times \boldsymbol{\psi}_{c}\right|=\frac{3 p_{r}}{2 \sigma L_{c}}\left|\boldsymbol{\psi}_{p c}\right|\left|\boldsymbol{\psi}_{c}\right| \sin \delta
$$

where $\sigma=1-L_{p c}^{2} /\left(L_{p} L_{c}\right)$ represents the leakage factor; $\psi_{c}$ and $\boldsymbol{\psi}_{p c}$ indicate the flux linkage vector of control winding and mutual flux linkage between the two stator windings, respectively, $\Psi_{p c}=\left(L_{p c} / L_{p}\right) \Psi_{p}$, and $\delta$ is the angle between them.

\section{Maximun Power Point Tracking of BDFRG}

According to [14], for making full use of the wind energy, $\beta$ should be as small as possible. If the actual wind speed is below the rating, usually $\beta=0^{\circ}$ to capture the maximum power shown as Fig. 4 , where $\beta\left(^{\circ}\right), \lambda, C_{p}, v_{w}(\mathrm{~m} / \mathrm{s}), n_{r}(\mathrm{rpm})$ and $P_{m}(\mathrm{~kW})$ represent the pitch angle, tip speed ratio and wind power utilization coefficient, wind speed, mechanical power and rotor speed of BDFRG, respectively. Notice that every power curve has a maximum power point tracking corresponds to each rotor speed depicted as Fig. 4 (b). Therefore, the MPPT can be realized if only $n_{r}$ is timely adjusted with regard to its maximum power point.

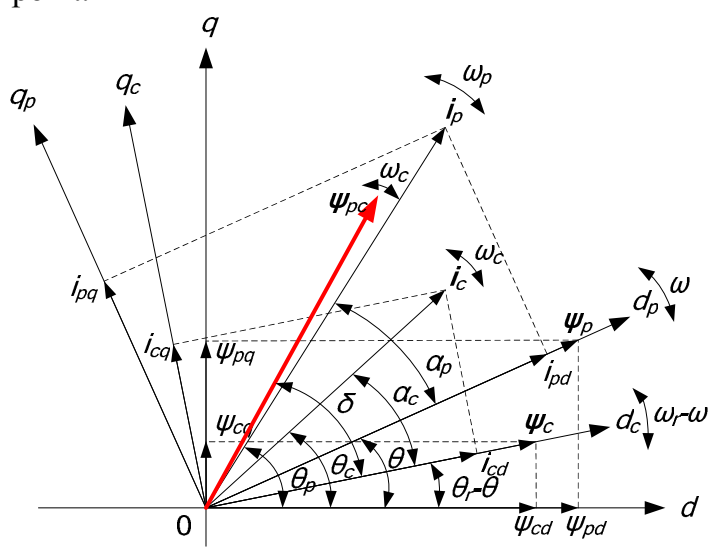

Fig. 3. The $d-q$ reference frames and inter-relationships between flux linkage and current.

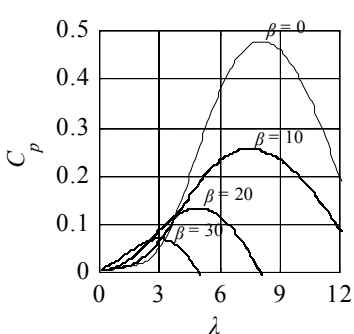

(a)

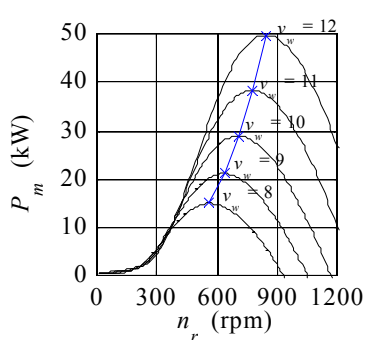

(b)
Fig. 4. Characteristics curve of wind turbine. (a) $\mathrm{C}_{p}-\lambda$ curves with different $\beta$ and (b) $P_{m}-n_{r}$ curves with different speed.

\section{DPC STRATEGY WITH CMV ELIMINATION}

\section{A. Topology of the Dual Two-level Converters}

As shown in Fig. 2, the control winding is open-circuited, and fed by the dual traditional two-level quadrant converters (MSC1 and MSC2) using a common dc bus, which is further elaborated in Fig. 5, then the voltage expressions of control phase windings can be represented as (7) and (8),

$$
\begin{gathered}
\left\{\begin{array}{l}
u_{c a}=u_{a 1 O}-u_{a 2 O}=u_{a 1 a 2} \\
u_{c b}=u_{b 1 O}-u_{b 2 O}=u_{b 1 b 2} \\
u_{c c}=u_{c 1 O}-u_{c 2 O}=u_{c 1 c 2}
\end{array}\right. \\
u_{c}(t)=\frac{2}{3}\left[u_{c a}(t)+u_{c b}(t) e^{\mathrm{j} \frac{2}{3} \pi}+u_{c c}(t) e^{\mathrm{j} \frac{4}{3} \pi}\right]
\end{gathered}
$$

As shown in Fig. 5, the traditional voltage vector diagram in each two-level converters can be illustrated in Fig. 6 (a), (b), which correspond to the MSC1 and MSC2, respectively.

\section{B. Selection and Optimization of Voltage Space Vector Combinations}

As shown in Fig. 7, the total switching modes of the dual twolevel converters increased to $2^{3} \times 2^{3}=64$ denoted as $11^{\prime}-88^{\prime}$ and divided into 24 smaller sectors, which obtained the same voltage vectors $(\mathbf{O A}, \ldots, \mathbf{O S})$ as traditional three-level converter [11], but its redundancy and fault tolerance are much higher the latter $(64>27)$, whereas the dc link voltage only half of the latter.

Here, the CMV in control winding expressed as (9), e.g., for the vector combination $24^{\prime}$, the CMV is 0 as (10). Then the combinations shown in Fig. 7 with $\mathrm{CMV}=0$ are the vectors $\mathbf{O H}$, OJ, OL, ON, OQ, OS and $O$.

$$
\begin{aligned}
& \left\{\begin{array}{l}
u_{\mathrm{CMV} 1}=\frac{u_{a 1 O}+u_{b 1 O}+u_{c 1 O}}{3} \\
u_{\mathrm{CMV} 2}=\frac{u_{a 2 O}+u_{b 2 O}+u_{c 2 O}}{3} \\
u_{\mathrm{CMV}}=u_{\mathrm{CMV} 1}-u_{\mathrm{CMV} 2}
\end{array}\right. \\
& u_{\mathrm{CMV}}=\left(U_{d c} / 2+U_{d c} / 2+0\right) / 3-\left(0+U_{d c} / 2+U_{d c} / 2\right) / 3=0
\end{aligned}
$$

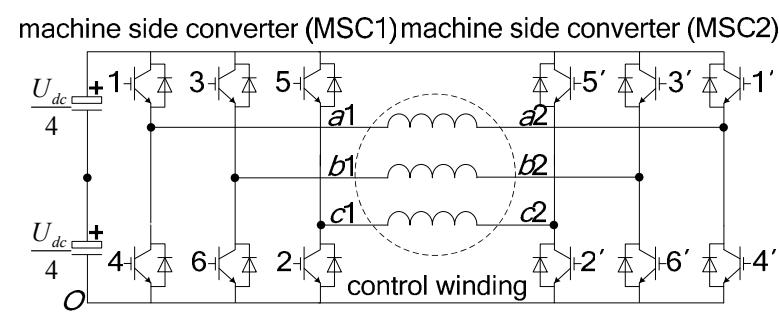

Fig. 5. Topology of open-winding BDFRG with dual two-level converters. 
(a)

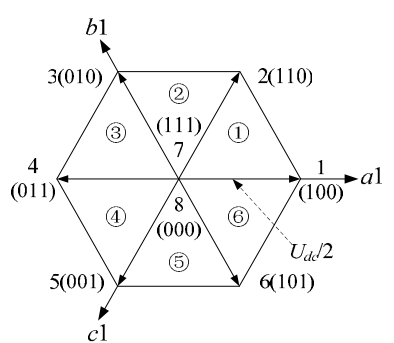

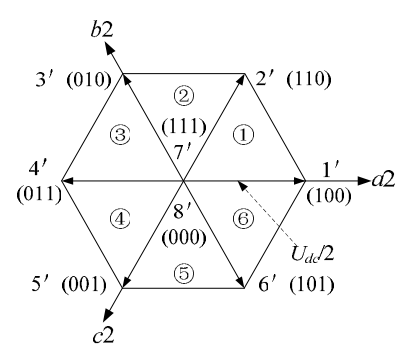

(b)
Fig. 6. Voltage space vector in each converter. (a) MSC1 and (b) MSC2.

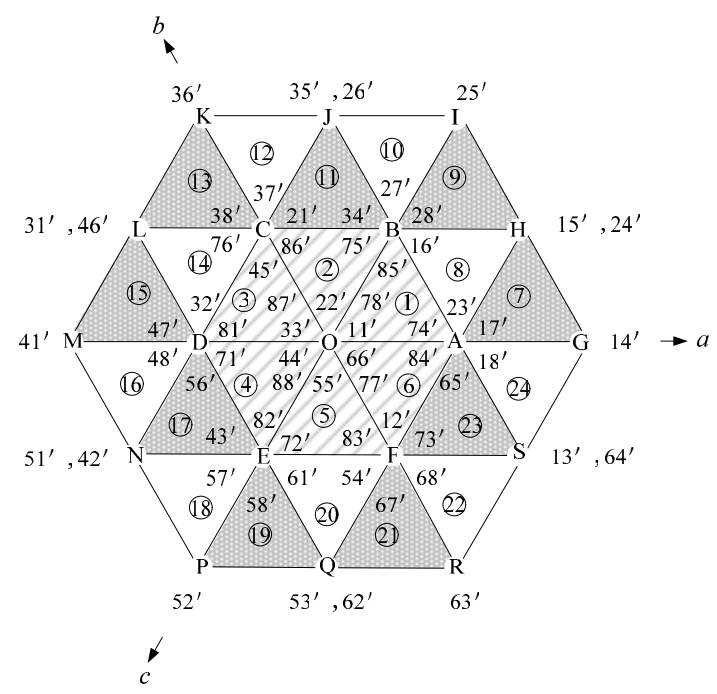

Fig. 7. The space phasors of proposed dual two-level converters.

\section{Main Ideas of the DPC Strategy}

Using the instantaneous power theory, then the power winding active and reactive power expressions can be represented as (11).

$$
\left\{\begin{array}{l}
P_{p}=\frac{3}{2}\left(u_{p q} i_{p q}+u_{p d} i_{p d}\right) \\
Q_{p}=\frac{3}{2}\left(u_{p q} i_{p d}-u_{p d} i_{p q}\right)
\end{array}\right.
$$

According to (5), by neglecting the copper losses and variation of energy stored in magnetic field [5], [6], the instantaneous real power is nearly equal to its mechanical power, i.e., $P_{p m} \approx P_{p}$. With referring to the DTC scheme [7] and having the flux linkage expressions given as (12), (13) respectively, then the principle of proposed DPC strategy about the $P_{p}$ can be explained (not for control) as follows: since the power winding is directly gridconnected, and the line frequency and voltage amplitude kept constant, then $\Psi_{p} \approx$ constant and hence $\Psi_{p c} \approx$ constant, as a result, $P_{p}$ can be increased/decreased with increasing/decreasing the $\delta$ as in (5), (6). While $Q_{p}$ can be elaborated logically as follows: since BDFRG flux is established by doubly-excited stator systems, i.e., if the control winding contributes more/less flux, then the power winding can contribute less/more, and vice versa. Hence $Q_{p}$ can be increased/decreased by increasing/decreasing the magnetizing current $\left(\Psi_{p}\right)$ implemented by decreasing/increasing the related control winding component from the controllable MSCs (vector combinations, hence the $\Psi_{c}$ ), this is the key fundamentals behind the DPC strategy of BDFRG [8].

$$
\begin{aligned}
& \left\{\begin{array}{l}
\boldsymbol{\psi}_{p}=\int\left(\boldsymbol{u}_{p}-R_{p} \boldsymbol{i}_{p}\right) d t \\
\boldsymbol{\psi}_{c}=\int\left(\boldsymbol{u}_{c}-R_{c} \boldsymbol{i}_{c}\right) d t
\end{array}\right. \\
& \left\{\begin{array}{l}
\psi_{c d}=\int\left(u_{c d}-i_{c d} R_{c}\right) d t \\
\psi_{c q}=\int\left(u_{c q}-i_{c q} R_{c}\right) d t
\end{array}\right.
\end{aligned}
$$

\section{The Relationship between Power Variations and Voltage} Space Vector Combinations

To implement the proposed DPC strategy of using the preselected control winding voltage vector combinations with CMV elimination, the span with selected vector combinations is redivided into six sectors (I-VI) shown as Fig. 8, where assuming that the $\psi_{c}$ lay in sector I at a given moment, and the $\psi_{p c}$ is ahead of $\psi_{c}$ with $\delta$, therefore, $P_{p}<0$, i.e., BDFRG absorbs mechanical power $\left(P_{p m}<0\right.$, ) from the wind turbine and generates electric power $\left(P_{p}\right)$ to the grid. With applying the voltage space vector combination either $26^{\prime}$ or $46^{\prime}$ wound result in the $\psi_{c}$ rotating anticlockwise, the angular $\delta$ to decrease, and the $P_{p}$ to increase (i.e., to become less negative), which meant that BDFRG would generate less electric power to the grid; for another, the vector combination either $62^{\prime}$ or $64^{\prime}$ would make $\psi_{c}$ to rotate clockwise, $\delta$ to increase, $P_{p}$ to decrease (i.e., more negative) and generate more power. Referring to the pre-declared relationship between $Q_{p}, \Psi_{p}$ and $\Psi_{c}$ (hence the control winding voltage vector combinations) in the section III. C, applying any vector combinations of $24^{\prime}, 26^{\prime}$ or $64^{\prime}$ would increase $\psi_{c} d$-axis component $\left(\Psi_{c d}\right)$ as shown in Fig. 3, as well as the $\Psi_{c}$, which implied that the control winding would contribute more reactive power to build field, hence the $Q_{p}$ would be decreased; on the contrary, vector combinations $42^{\prime}, 46^{\prime}$ or $62^{\prime}$ would have the completely opposite effects, i.e., would reduce $\psi_{c}$.

For easily understanding the DPC strategy proposed above , the relationship between $Q_{p}$, sectors and vector combinations are given in Tabs. I-III, where $P_{\text {pref }}, Q_{\text {pref }}, \Delta P$ and $\Delta Q$ represent the reference values of $P_{p}, Q_{p}$ and half of the width of hysteresis comparator, respectively; "+", “-” indicate $Q_{p}$ will be increased or decreased with applying the selected vector combinations, " $\mathrm{x}$ " shows the combinations to be abandoned due to causing drastic change in $Q_{p}$; “+1", "-1" denote the sector number is to be increased ( $\boldsymbol{\psi}_{c}$ anti-clockwise)/decreased ( $\boldsymbol{\psi}_{c}$ clockwise) with the selected vector combinations. Obviously, there is only one vector combinations selected can control both $P_{p}$ and $Q_{p}$ at a given time 
(or sector), e.g., if the $\psi_{c}$ lay in sector I, only the selected vector combinations $46^{\prime}$ can both increase $P_{p}$ and $Q_{p}$.

Particularly, in order to simplify the proposed DPC strategy, the zero vector combinations are not adopted because of contributing a completely reverse effect on $Q_{p}$ in "subsynchronous" and "super-synchronous" modes, and the other scheme has also been abandoned due to the same effect as the proposed manner according to Table. I.

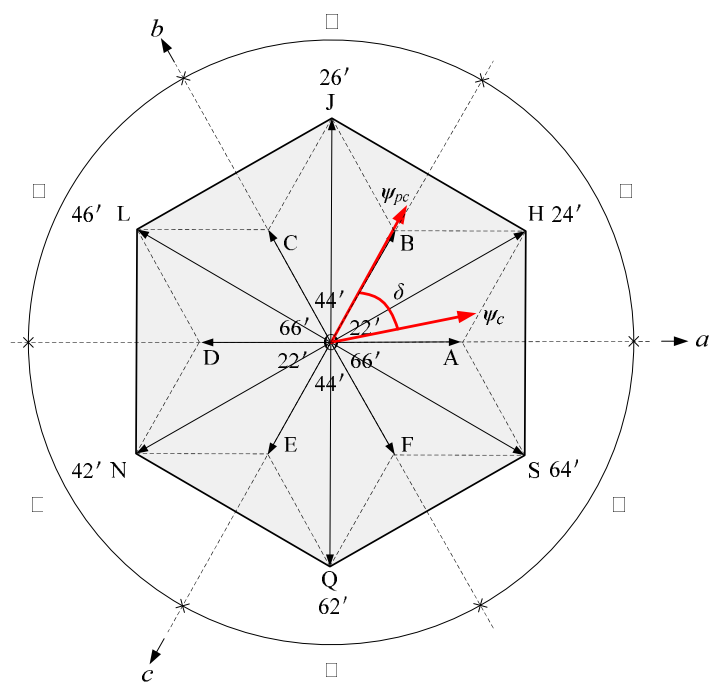

Fig. 8. Sectors re-divided with selected voltage space vector combinations

TABLE I. EXPECTED CHANGE RATE OF $Q_{P}$

\begin{tabular}{|c|c|c|c|c|c|c|}
\hline Sector/Vector & $24^{\prime}$ & $26^{\prime}$ & $46^{\prime}$ & $42^{\prime}$ & $62^{\prime}$ & $64^{\prime}$ \\
\hline I & $\mathrm{x}$ & - & + & $\mathrm{x}$ & + & - \\
\hline II & - & $\mathrm{x}$ & - & + & $\mathrm{x}$ & + \\
\hline III & + & - & $\mathrm{x}$ & - & + & $\mathrm{x}$ \\
\hline IV & $\mathrm{x}$ & + & - & $\mathrm{x}$ & - & + \\
\hline V & + & $\mathrm{x}$ & + & - & $\mathrm{x}$ & - \\
\hline VI & - & + & $\mathrm{x}$ & + & - & $\mathrm{x}$ \\
\hline
\end{tabular}

TABLE II. OPTIMUM OF SWITCHING VECTORS

\begin{tabular}{|c|c|c|c|c|c|c|c|}
\hline \multicolumn{2}{|c|}{ Error } & \multicolumn{6}{|c|}{ Sector } \\
\hline$P_{\text {pref }}-P_{p}$ & $Q_{\text {pref }}-Q_{p}$ & I & II & III & IV & V & VI \\
\hline$\leq-\Delta P_{p}$ & $\leq-\Delta Q_{p}$ & $64^{\prime}$ & $24^{\prime}$ & $26^{\prime}$ & $46^{\prime}$ & $42^{\prime}$ & $62^{\prime}$ \\
\hline$\leq-\Delta P_{p}$ & $>\Delta Q_{p}$ & $62^{\prime}$ & $64^{\prime}$ & $24^{\prime}$ & $26^{\prime}$ & $46^{\prime}$ & $42^{\prime}$ \\
\hline$>\Delta P_{p}$ & $\leq-\Delta Q_{p}$ & $26^{\prime}$ & $46^{\prime}$ & $42^{\prime}$ & $62^{\prime}$ & $64^{\prime}$ & $24^{\prime}$ \\
\hline$>\Delta P_{p}$ & $>\Delta Q_{p}$ & $46^{\prime}$ & $42^{\prime}$ & $62^{\prime}$ & $64^{\prime}$ & $24^{\prime}$ & $26^{\prime}$ \\
\hline
\end{tabular}

TABLE III. Deduced Direction Of SECTOR CHANGE

\begin{tabular}{|c|c|c|c|c|c|c|}
\hline Sector/Vector & $24^{\prime}$ & $26^{\prime}$ & $46^{\prime}$ & $42^{\prime}$ & $62^{\prime}$ & $64^{\prime}$ \\
\hline I & $\mathrm{x}$ & -1 & +1 & $\mathrm{x}$ & -1 & +1 \\
\hline $\mathrm{II}$ & +1 & $\mathrm{x}$ & -1 & +1 & $\mathrm{x}$ & -1 \\
\hline $\mathrm{III}$ & -1 & +1 & $\mathrm{x}$ & -1 & +1 & $\mathrm{x}$ \\
\hline $\mathrm{IV}$ & $\mathrm{x}$ & -1 & +1 & $\mathrm{x}$ & -1 & +1 \\
\hline V & +1 & $\mathrm{x}$ & -1 & +1 & $\mathrm{x}$ & -1 \\
\hline VI & -1 & +1 & $\mathrm{x}$ & -1 & +1 & $\mathrm{x}$ \\
\hline
\end{tabular}

\section{SiMULATION STUDIES}

To evaluate the performance of proposed DPC strategy, the simulation model is established in MATLAB/Simulink ${ }^{\circledR}$ as shown in Fig. 2, and the BDFRG parameters as follows: $P_{N}=42$ $\mathrm{kW}, U_{N p}=U_{N c}=380 \mathrm{~V}, p_{p}=3, R_{p}=0.1662 \Omega, L_{p}=0.01737 \mathrm{H}$, $L_{p c}=0.01813 \mathrm{H}, p_{c}=1, R_{c}=0.1882 \Omega, L_{c}=0.02351 \mathrm{H}, J=0.3$ $\mathrm{kg} \cdot \mathrm{m}^{2}[12]$.

Setting $U_{d c}=100 \mathrm{~V}, \Delta P_{p}= \pm 0.4 \mathrm{~kW}, \Delta Q_{p}= \pm 0.3 \mathrm{kvar}$; the given wind speed (with high-frequency random white noise signal to account for practical effects of speed vibration and voltage/current transducers resolution) is $8 \mathrm{~m} / \mathrm{s}$ started at $0 \mathrm{~s}$, stepped to $9 \mathrm{~m} / \mathrm{s}, 10 \mathrm{~m} / \mathrm{s}$ at $1.8 \mathrm{~s}$ and $3.6 \mathrm{~s}$ respectively; the given $Q_{\text {pref }}=0$ kvar so as to keep the power factor nearly to 1 .

Starting procedure is irrelevant for this paper and not shown in the results, then some simulation results of the proposed DPC strategy are presented in Figs. 9-13.

As shown in Figs. 9 and 10, power winding $P_{p}$ can quickly track the derived MPPT values as $-11.3 \mathrm{~kW},-15.8 \mathrm{~kW}$ and -21.8 $\mathrm{kW}$ (as MPPT illustrated in Section II. C), at the same time, $Q_{p}$ is kept almost $0 \mathrm{kVar}$. Fig. 11 illustrates the control winding current in phase $a$ according to VSCF and DPC, its frequency is $-12.3 \mathrm{~Hz},-7.7 \mathrm{~Hz}$ and $-2.9 \mathrm{~Hz}$ respectively (when the frequency value in power winding is kept about $50 \mathrm{~Hz}$ ). Fig. 12 shows the sectors of voltage space vector combinations in dual two-level converters illustrated in Fig. 7, which corresponds to Tab. I-III. Fig. 13 demonstrates the CMV of the proposed DPC strategy for open-winding BDFRG, where the CMV is eliminated to approximately $0 \mathrm{~V}$, then common mode current and shaft current of the proposed system can also nearly to 0 .

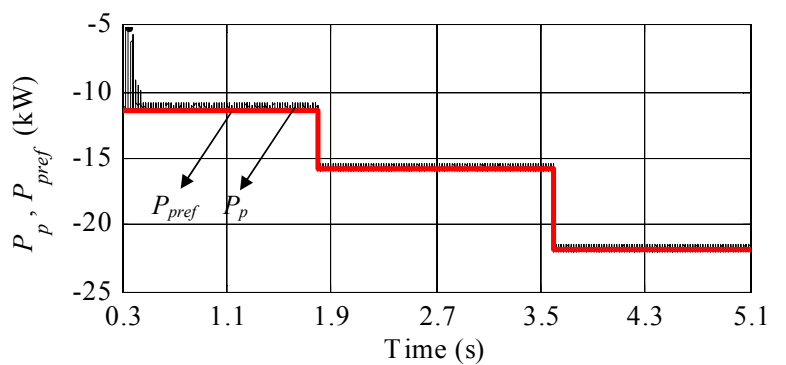

Fig. 9. Active power and its enlarged vision of $P_{\text {pref }}$ and $P_{p}$ in power winding.

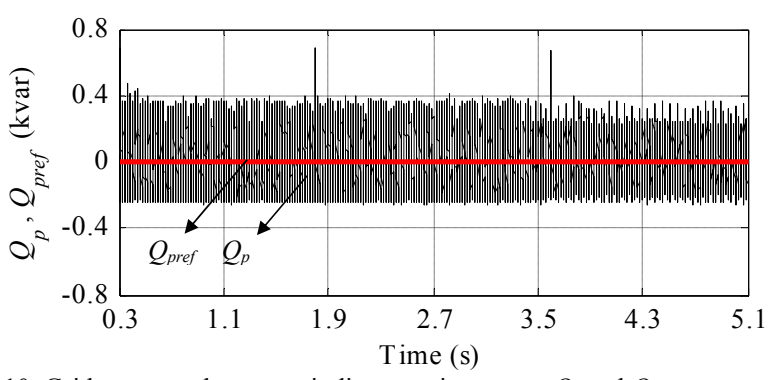

Fig. 10. Grid connected power winding reactive power $Q_{p}$ and $Q_{p r e f}$ 


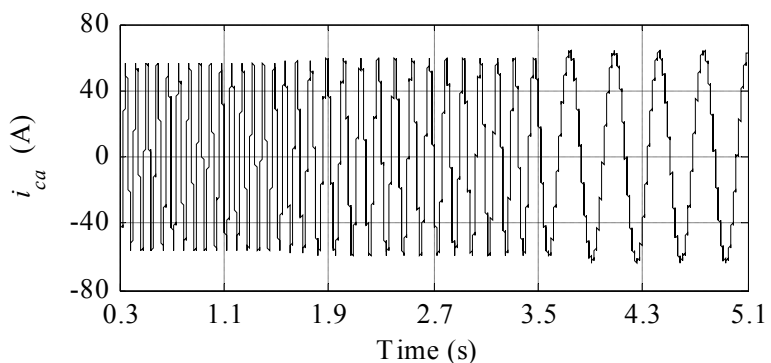

Fig. 11. Control winding current and its enlarged view in phase $a$.

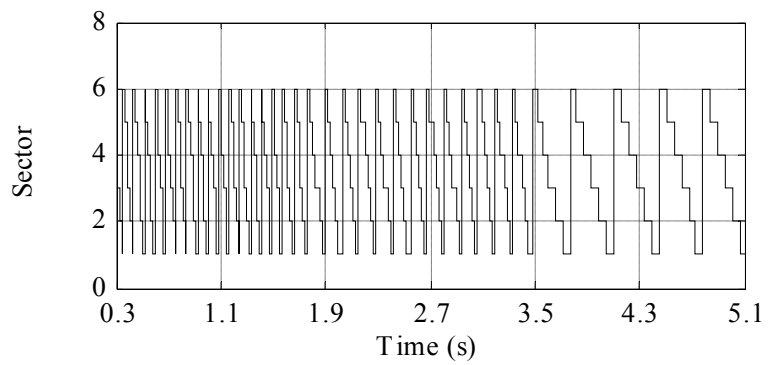

Fig. 12. Sectors of voltage space vector combination in dual two-level converters.

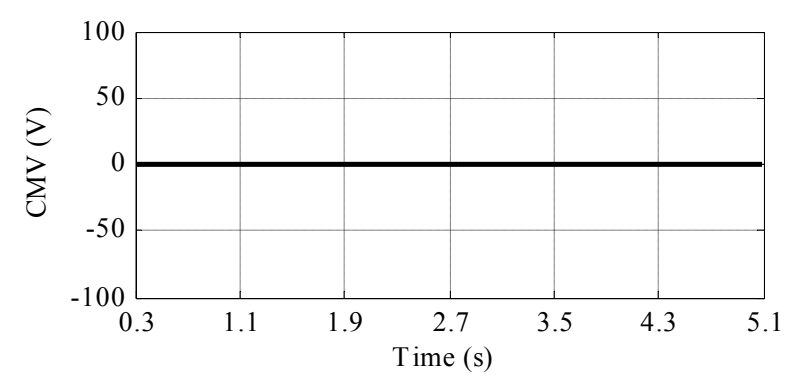

Fig. 13. Control winding of the common mode voltage (CMV).

\section{Conclusions}

This paper has presented a novel direct power control (DPC) with common mode voltage elimination (CMV) for openwinding brushless doubly-fed wind power generators. The feasibility of the proposed DPC strategy is evaluated by simulation tests, and the advantages of the proposed system are simpler in main circuit, more convenient control scheme, lower DC-link voltage while achieving higher redundancy and better fault tolerance than existing conventional three-level converter systems. It can provide a good reference to further research (at present) about relevant control strategy and implement prototype experimental platform. The experimental verification of such control approach is currently in progress and will be published in our future papers.

\section{REFERENCES}

[1] F. X. Wang, F. G. Zhang and L. Y. Xu, "Parameter and performance comparison of doubly fed brushless machine with cage and reluctance rotors," IEEE Trans. Ind. Appl., vol. 38, no. 5, pp. 1237-1243, Sept. -Oct. 2002.

[2] R. E. Betz and M. G. Jovanovic, "The Brushless Doubly Fed Reluctance Machine and the Synchronous Reluctance Machine-A Comparison," IEEE Trans. Ind. Appl., vol. 36, no. 4, pp.1103-1108, Jul. -Aug. 2000.

[3] M. G. Jovanovic, R. E. Betz, and J. Yu, "The use of doubly fed reluctance machines for large pumps and wind turbines," IEEE Trans. Ind. Appl., vol. 38, no. 6, pp. 1508-1516, Nov. -Dec. 2002.

[4] R. Cardenas, R. Pena, S. Alepuz, and G. Asher, "Overview of control systems for the operation of DFIGs in wind energy applications," IEEE Trans. Ind. Electron., vol. 60, no. 7, pp. 2776-2798, Jul. 2013.

[5] S. Ademi and M. G. Jovanović, "Vector Control Methods for Brushless Doubly Fed Reluctance Machines," IEEE Trans. Ind. Electron., vol. 62, no. 1, pp. 96-104, Jan. 2015.

[6] S. Ademi, M. G. Jovanovic, H. Chaal and W. Cao, "A New Sensorless Speed Control Scheme for Doubly Fed Reluctance Generators," IEEE Trans. Energy Convers., vol. 31, no.6, pp.993-1001, Sept. 2016.

[7] M. G. Jovanovic, J. Yu, and E. Levi, "Encoderless direct torque controller for limited speed range applications of brushless doubly fed reluctance motors," IEEE Trans. Ind. Appl., vol. 42, no. 3, pp. 712-722, May-Jun. 2006.

[8] Chaal H., Jovanovic M. "Improved direct torque control using Kalman filter: application to a doubly-fed machine," in the 11th IASTED International Conference on Control and Applications, Cambridge, UK, Jul. 2009.

[9] H. Chaal and M. G. Jovanovic, "Power control of brushless doubly-fed reluctance drive and generator systems," Renew. Energy, vol. 37, no. 1, pp. 419-425, Jan. 2012.

[10] Boller T., Holtz J., and Rathore A. K., "Optimal pulsewidth modulation of a dual three-level inverter system operated from a single dc link," IEEE Trans. Ind. Appl., vol. 48, no. 5, pp. 1610-1615, Sept. -Oct. 2012.

[11] A. Nabae, I. Takahashi, and H. Akagi, "A new neutral-point-clamped PWM inverter,” IEEE Trans. Ind. Appl., vol. IA-17, no. 5, pp. 518-523, Sept. 1981.

[12] F. Zhang, L. Zhu, S. Jin, W. Cao, D. Wang, and J. L. Kirtley, "Developing a New SVPWM Control Strategy for Open-Winding Brushless Doubly Fed Reluctance Generators," IEEE Trans. Ind. Appl., vol. 51, no. 6, pp. 45674574, Nov. -Dec. 2015.

[13] S. Srinivas and K. Ramachandra Sekhar, "Theoretical and experimental analysis for current in a dual-inverter-fed open-end winding induction motor drive with reduced switching PWM," IEEE Trans. Ind. Electron., vol. 60 , no. 10 , pp. $4318-4328$, Oct. 2013.

[14] K. R. Sekhar and S. Srinivas, "Discontinuous Decoupled PWMs for Reduced Current Ripple in a Dual Two-Level Inverter Fed Open-End Winding Induction Motor Drive," IEEE Trans. Power Electron., vol. 28, no. 5, pp. 2493-2502, May 2013.

[15] Ademi S. and Jovanovic M., "High-efficiency control of brushless doublyfed machines for wind turbines and pump drives," Energy Convers. Manage., vol. 81, no. 5, pp. 120-132, May 2014.

[16] Ademi S. and Jovanovic M., "Control of doubly-fed reluctance generators for wind power applications," Renew. Energy, vol. 85, pp. 171-180, Jan 2016. 